$$
\text { CONF- } 960826--3
$$

\title{
CELL ASYMMETRY CORRECTION FOR TEMPERATURE MODULATED DIFFERENTIAL SCANNING CALORIMETRY
}

\author{
K. Ishikiriyama ${ }^{\mathrm{a}}$ and $\mathrm{B}$. Wunderlich*
}

Department of Chemistry, The University of Tennessee, Knoxville, TN 37996-1600, USA, and Chemistry and Analytical Sciences Division, Oak Ridge National Laboratory, Oak Ridge, TN 37831-6197, USA

(Received

Abstract: The quality of measurement of heat capacity by differential scanning calorimetry (DSC) is based on strict symmetry of the twin calorimeter. This symmetry is of particular importance for temperature-modulated DSC (TMDSC) since positive and negative deviations from symmetry cannot be distinguished in the most popular analysis methods. The heat capacities for sapphire-filled and empty aluminum calorimeters (pans) under designed cell imbalance caused by different pan-masses were measured. In addition, the positive and negative signs of asymmetry have been explored by analyzing the phase-shift between temperature and heat flow for sapphire and empty runs. The phase shifts change by more than $180^{\circ}$ depending on the sign of the asymmetry. Once the sign of asymmetry is determined, the asymmetry correction for modulated DSC can be made.

Keywords:temperature-modulated differential scanning calorimetry, TMDSC, heat capacity, heat flux calorimeter, asymmetry correction, calibration, phase angle
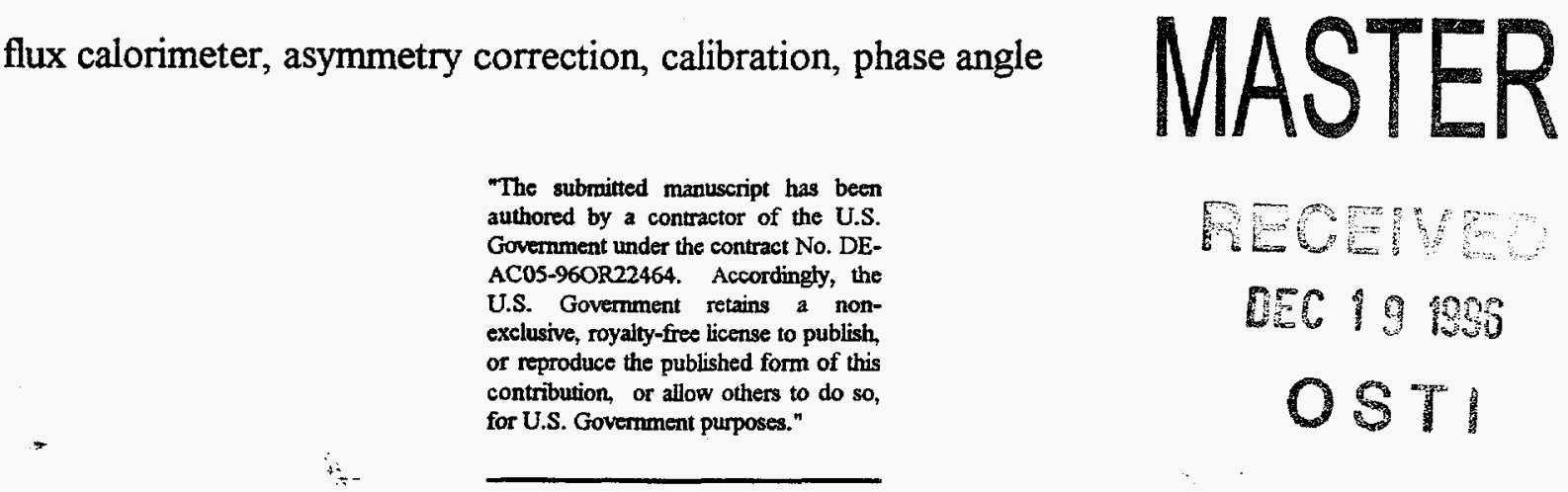

a On leave from Toray Research Center, Inc., Otsu, Shiga 520, Japan 


\section{DISCLAMMER}

This report was prepared as an account of work sponsored by an agency of the United States Government. Neither the United States Government nor any agency thereof, nor any of their employees, makes any warranty, express or implied, or assumes any legal liability or responsibility for the accuracy, completeness, or usefulness of any information, apparatus, product, or process disclosed, or represents that its use would not infringe privately owned rights. Reference herein to any specific commercial product, process, or service by trade name, trademark, manufacturer, or otherwise does not necessarily constitute or imply its endorsement, recommendation, or favoring by the United States Government or any agency thereof. The views and opinions of authors expressed herein do not necessarily state or reflect those of the United States Government or any agency thereof. 


\section{DISCLAMMER}

Portions of this document may be illegible in electronic image products. Images are produced from the best available original document. 


\section{Introduction}

Twin calorimetry has been used to reduce the basic problem of any heat measurement, the heat loss or gain due to extraneous flux. The differential measurement between a reference and a sample should approach equal losses for both calorimeters and thus needs only a minor correction for residual asymmetry. In a previous paper [1], the basic problem arising from any remaining asymmetry of the two calorimeters was measured for standard differential scanning calorimeters (DSCs) and the implications for temperature-modulated DSC (TMDSC) were discussed, such as for the Modulated DSC (MDSC ${ }^{\mathrm{TM}}$ ) of TA Instruments, the Dynamic DSC $\left(\mathrm{DDSC}^{\mathrm{TM}}\right)$ of Perkin-Elmer, and the Alternating DSC $\left(\mathrm{ADSC}^{\mathrm{TM}}\right)$ of Mettler. Also, the simple recipe to introduce an asymmetry of known direction had been proposed to avoid potentially large errors.

As is well known from heat capacity measurement by standard DSC, the heat flow of a run with identical, empty pans must always be subtracted from runs with sample and standard samples [2]. The positive or negative deviation from zero for this empty run is the asymmetry. The sign of the asymmetry is in the case of standard DSC of no concern since it has the same sign as the contributions of the identical pans in the sample and standard runs. In TMDSC, in contrast, the empty run registers a positive heat flow for both, positive and negative deviations from zero. Therefore, the determination of the sign of the asymmetry is of importance for heat capacity measurement of higher precision.

In this work, heat capacities was determined for sapphire and pairs of empty calorimeters of varying aluminum content (asymmetry) using the quasi-isothermal measuring condition of MDSC $[3,4]$. Quasi-isothermal measurements involve modulation at a fixed base temperature 
$T_{\mathrm{o}}$, so that the sample temperature is $T_{\mathrm{s}}=T_{\mathrm{o}}+A \sin (\mathrm{w} t-\varepsilon)$ with $\varepsilon$ representing the phase lag between heater and sample calorimeters. The results have been analyzed using the changes in phase lag. A recipe for determination of the sign of the asymmetry correction based on the phase shift will be described.

\section{Mathematics of the Measurement by TMDSC}

In standard DSC heat capacity can be determined when two conditions are fulfilled [2]: 1.) steady state is reached throughout the instrument, i.e. the heating rate $q=\mathrm{d} T / \mathrm{d} t$ is the same at any point in the DSC enclosed by the heater; and 2 .) the temperature gradient within the sample and reference calorimeters is negligible. Using Newton's law of cooling, one can write under these conditions for either calorimeter (aluminum pan and its content):

$$
\frac{\mathrm{d} Q}{\mathrm{~d} t}=K\left[T_{\mathrm{b}}(t)-T(t)\right]
$$

where $T_{\mathrm{b}}$ is the block or heater temperature, $Q$ is the heat exchanged, and $K$ is the geometry and material-dependent constant describing the heat flow for the path from heater to sample or reference calorimeter. The respective heat flows change the temperature of the sample or reference calorimeters proportionally to their corresponding heat capacities $C_{\mathrm{s}}$ and $C_{r}$, respectively, and one can derive for the temperature difference between the two calorimeters the following basic equation [2]:

$$
T_{\mathrm{r}}-T_{\mathrm{s}}=\frac{\left(C_{\mathrm{s}}-C_{\mathrm{r}}\right)}{K} \frac{d T_{\mathrm{s}}}{d t}-\frac{C_{\mathrm{r}}}{K} \frac{d\left(T_{\mathrm{r}}-T_{\mathrm{s}}\right)}{d t}
$$

The heat capacity is then approximately $\left(\Delta T=T_{r}-T_{s}\right)$ : 


$$
m c_{\mathrm{p}} \approx K \frac{\Delta T}{q}
$$

where $m$ is the sample mass and $c_{p}$ is the specific heat capacity of the sample. A more precise equation that corrects for the difference in heating rate between reference and sample calorimeters due to changing heat capacities is available [2] and can easily be corrected for. Any asymmetry has an equal effect on empty, sample, and reference runs.

Measuring with TMDSC is different. In this case one inserts complex expressions for temperature and temperature difference into Eq.(2) and finds the following solutions for the imaginary and real parts $[4,5]$ :

$$
\begin{aligned}
& \cos (\varepsilon-\delta)=\frac{K A_{\Delta}}{A \omega\left(C_{\mathrm{s}}-C_{\mathrm{r}}\right)} \\
& \sin (\varepsilon-\delta)=-\frac{A_{\Delta} C_{\mathrm{r}}}{A\left(C_{\mathrm{s}}-C_{\mathrm{r}}\right)}
\end{aligned}
$$

where $A_{\Delta}$ is the maximum modulation amplitude of $\Delta T$, and $A$ is the chosen amplitude of the modulation of the sample temperature. The phase lag $\varepsilon$ refers to the lag of the sample temperature relative to the base modulation $\omega t(\omega=$ modulation frequency $2 \pi / p, p=$ modulation period in seconds) and $\delta$ refers to the phase lag of the temperature difference $\Delta T$. Furthermore, since $\sin ^{2}(\varepsilon-\delta)+\cos ^{2}(\varepsilon-\delta)=1$, one can also derive the expression for heat capacity:

$$
\begin{gathered}
1=\left(\frac{A_{\Delta} C_{\mathrm{r}}}{A\left(C_{\mathrm{s}}-C_{\mathrm{r}}\right)}\right)^{2}+\left(\frac{K A_{\Delta}}{A \omega\left(C_{\mathrm{s}}-C_{\mathrm{r}}\right)}\right)^{2} \\
\left|C_{\mathrm{s}}-C_{\mathrm{r}}\right|=\frac{A_{\Delta}}{A} \sqrt{\left(\frac{K}{\omega}\right)^{2}+C_{\mathrm{r}}^{2}}
\end{gathered}
$$


Note that because of the square root, $C_{s}-C_{r}$ may be positive or negative. For a typical measurement involving a filled sample pan and empty pan it is obvious that only the positive solution is valid since heat capacity can only be positive. For similar heat capacities of sample and reference calorimeters, the solution is not obvious.

For a given modulation frequency and identical masses of reference and sample pans, one might be tempted to use the same equation as applies for standard DSC to calculate the sample heat capacity, namely:

$$
m c_{\mathrm{p}}=m_{\mathrm{Al}_{2} \mathrm{O}_{3}} c_{\mathrm{p}}\left(\mathrm{Al}_{2} \mathrm{O}_{3}\right) \frac{a_{\mathrm{s}}-a_{\mathrm{b}}}{a_{\mathrm{c}}-a_{\mathrm{b}}}
$$

where the symbols $a$ represent the maximum heat flow amplitudes of the temperature differences of the sample run (s), the calibration run (c, with sapphire, $\mathrm{Al}_{2} \mathrm{O}_{3}$ ), and the baseline run (b, with two empty aluminum pans, identical in weight to the other two runs). Because of the square root in Eq.(7) there is, now, a significant difference for TMDSC compared to DSC. In the case of an empty pan on the reference position that is identical to the sample pan, the heat capacity is, according to Eq. (7):

$$
m c_{\mathrm{p}}=\frac{A_{\Delta}}{A} \sqrt{\left(\frac{K}{\omega}\right)^{2}+C^{\prime 2}}=\frac{A_{\mathrm{HF}}}{A \omega} K_{\mathrm{c}}
$$

where $C^{\prime}$ is the heat capacity of the empty reference calorimeter and $K_{\mathrm{c}}$ is the calibration constant for heat flow for a given empty reference pan as used in the standard analysis procedure: If a cell asymmetry, $\Delta C_{\text {cell }}$, and differences between the aluminum pans exist, one writes $C_{\mathrm{s}}^{\prime}$ and $C_{\mathrm{r}}^{\prime}$ for the heat capacities of the pans, and finds that:

$$
\left|C_{\mathrm{s}}-C_{\mathrm{r}} \pm \Delta C_{\text {cell }}\right|=\left|m c_{\mathrm{p}}+C_{\mathrm{s}}^{\prime}-C_{\mathrm{r}}^{\prime} \pm \Delta C_{\text {cell }}\right|=K_{\mathrm{c}} \frac{A_{\mathrm{HF}}}{A \omega}
$$


In the case of standard and sample runs, the values within the absolute value bars must be positive because of a positive heat capacity of the $\mathrm{Al}_{2} \mathrm{O}_{3}$ standard and the sample. In the case of the baseline run with two empty pans, $m c_{\mathrm{p}}=0$ and $C_{\mathrm{s}}^{\prime} \approx C_{\mathrm{r}}^{\prime} \approx 0$, so that $\Delta C_{\text {cell }}$ is the only significant contribution. Its sign can not be obtained from Eq. (10).

To resolve this difficulty we studied a series of runs of $\mathrm{Al}_{2} \mathrm{O}_{3}$ with different sample and reference aluminum pans to induce known asymmetries into the experiments. The following equations can then be written for the properly corrected $\mathrm{Al}_{2} \mathrm{O}_{3}$ heat capacity $C_{\mathrm{s}}{ }^{\mathrm{c}}\left(\mathrm{Al}_{2} \mathrm{O}_{3}\right)$ :

$$
C_{\mathrm{s}}^{\mathrm{c}}\left(\mathrm{Al}_{2} \mathrm{O}_{3}\right)=C_{\mathrm{s}}\left(\mathrm{Al}_{2} \mathrm{O}_{3}\right)-C^{\prime}(\text { empty } \pm), \quad \text { if }\left(C_{\mathrm{s}}^{\prime}-C^{\prime}{ }_{r}\right) \geq \Delta C_{\text {cell }}
$$

and

$$
C_{\mathrm{s}}^{\mathrm{c}}\left(\mathrm{Al}_{2} \mathrm{O}_{3}\right)=C_{\mathrm{s}}\left(\mathrm{Al}_{2} \mathrm{O}_{3}\right)+C^{\prime}(\text { empty } \pm), \quad \text { if }\left(C^{\prime}{ }_{\mathrm{s}}-C^{\prime}{ }_{r}\right) \leq \Delta C_{\text {cell }}
$$

where $C_{\mathrm{s}}\left(\mathrm{Al}_{2} \mathrm{O}_{3}\right)$ and $C^{\prime}(\mathrm{empty} \pm)$ are the heat capacities measured during a sapphire run and an empty run, each with two aluminum pans of the same difference in weight as in the $\mathrm{Al}_{2} \mathrm{O}_{3}$ run.

\section{Experimental}

A commercial modulated DSC of TA Instruments Inc. (MDSC 2910) with a liquid nitrogen cooling accessory was used for the asymmetry study. Dry nitrogen with a flow rate of $20 \mathrm{~mL} / \mathrm{min}$ was purged through the DSC cell. The standard run (sapphire) and the baseline run (with two empty aluminum pans) were carried out by using reference pans of sizes ranging from 20-26 mg. The sapphire mass was always $41.535 \mathrm{mg}$ and for calibration its heat capacity was taken from the literature [5]. Measurements were conducted under quasi-isothermal conditions [6], using a modulation amplitude of $A=1.0 \mathrm{~K}$, coupled with periods $p$ of $60 \mathrm{~s}$ over the temperature range from 302 to $322 \mathrm{~K}$ with temperature $T_{\mathrm{o}}$ increasing in steps of $10 \mathrm{~K}$. In this 
paper, only selected results at 320 and $322 \mathrm{~K}$ are presented. Data were recorded after 10 minutes from the start of the run to assure steady state.

The heat flow was calibrated with the conventional DSC method using $41.535 \mathrm{mg}$ of sapphire. Temperature was calibrated from the onsets of the transition peaks for cyclohexane $(186.09 \mathrm{~K})$, octane $(216.15 \mathrm{~K})$, water $(273.15 \mathrm{~K})$, and indium $(429.75 \mathrm{~K})$.

\section{Results}

The measured heat capacities, $\mathrm{C}_{\mathrm{s}}\left(\mathrm{Al}_{2} \mathrm{O}_{3}\right)$ and $\mathrm{C}^{\prime}($ empty \pm ) and corresponding phase angles for the sapphire and empty baseline runs under quasi-isothermal conditions, are summarized in Tables 1 and 2 at the indicated temperatures. The heat capacities at $322 \mathrm{~K}$ are shown in Fig. 1 as a function of the difference in aluminum mass of the sample - reference pans, $\Delta m$, which corresponds to an artificial cell asymmetry. Before correction, the measured heat capacity of the sapphire, $C_{\mathrm{s}}\left(\mathrm{Al}_{2} \mathrm{O}_{3}\right)$, increases linearly with increasing $\Delta m$ (filled circles). The heat capacities of the empty runs, in contrast, have a break in $C$ '(empty \pm ) for $\Delta m \approx 0$ (open circles). Below $\Delta m \approx 0$, the heat capacity of the empty run, $C^{\prime}$ (empty \pm ), decreases linearly with $\Delta m$, and above it increases. These results prove that to remove the asymmetry introduced by $\Delta m$, Eq. (12) holds for the left half of Fig.1 $(\Delta m \leq 0)$ and Eq. (11) for the right half $(\Delta m \geq 0)$.

Magnifying the area about $\Delta m$ one finds an intrinsic imbalance of about $0.6 \mathrm{mg}$, as reported previously [1]. Accordingly, if the sample pan is $0.6 \mathrm{mg}$ heavier than the reference pan, the correct sapphire heat capacity, $\mathrm{C}_{\mathrm{s}}{ }^{\mathrm{c}}\left(\mathrm{Al}_{2} \mathrm{O}_{3}\right)$, should be obtained by subtraction of the empty baseline heat capacities from the sapphire heat capacities. After correction for the intrinsic and introduced asymmetry, the specific heat capacity that had a systematic RMS error of $16.2 \%$ 
(filled circles) has an acceptable error of $0,8 \%$ over the full range of measurements (open squares).

\section{Discussion}

Figure 1 proves the need to have an independent measure of the sign of the cell imbalance. It was suggested earlier that a sufficiently heavier sample pan would be advantageous. This would assure that the correction suggested by Eq. (8) would have the proper sign and, by choosing a sufficiently large discrepancy of the masses, would avoid the difficulty of finding a precise match of the intrinsic imbalance as a function of temperature and environment. About $2 \mathrm{mg}$ mass imbalance was suggested to be sufficient [1].

The slopes of the heat capacities versus $\Delta m$ in Fig. 1 can also be used for an estimate of the specific heat capacity of the aluminum of the empty pans. They yield about $1.0 \mathrm{~J} \mathrm{~g}^{-1} \mathrm{~K}^{-1}$, close to the specific heat capacity of $\mathrm{Al}\left(0.905 \mathrm{~J} \mathrm{~g}^{-1} \mathrm{~K}^{-1}\right)$ at $322 \mathrm{~K}$ [7]. For more precise measurements larger sample masses should be used. Deviations in calorimetric response are common for small sample masses.

To develop an independent method to establish the sign of the asymmetry we analyzed the phase shifts in the experiments. The shift of the heat flow on changing the asymmetry is given schematically in Fig. 2. In the case of a positive asymmetry in standard DSC, the initial heat flow of the baseline run with empty pans is endothermic (on the same side as the sapphire run on heating), and on cooling it is exothermic (dashed lines). The case of negative asymmetry is shown in schematic (b). For TMDSC, the same argument is valid. With positive asymmetry, both, the modulated heat flows of baseline and sapphire runs would start endothermically; 
whereas with negative asymmetry the modulated heat flow of the baseline run is on the exothermic side. This implies that a phase shift of $180^{\circ}$ should take place at the point of symmetry which could answer the question of the sign of the correction.

Figures 3 and 4 depict the modulated heat flows and temperatures and for $320 \mathrm{~K}$ and mass differences of $\Delta m=+3.1$ and $-3.2 \mathrm{mg}$, respectively (compare to runs R2 and R8 at $322 \mathrm{~K}$ in Tables 1 and 2). The phase shifts of both, the sapphire and the baseline runs are shown. The time scale of the modulated temperature curves for both runs were shifted to coincide. Figures 3 and 4 can be compared with Figs. 2 (a) and (b), respectively. In the case of positive asymmetry $\left(\Delta m=3.1 \mathrm{mg}>\Delta m_{\text {cell }}\right)$, the phase difference of the heat flow between the sample and baseline runs is $32^{\circ}$, i.e., the heat flows of sapphire and empty runs have similar phase angles. However, in the case of negative asymmetry $\left(\Delta m=-3.2 \mathrm{mg}<\Delta m_{\text {cell }}\right)$, the phase difference is $-184^{\circ}$, i.e., the heat flows of sample and reference are almost out of phase. Therefore, the expectation in Fig. 2 as to the phase shift is supported by experiment. The phase differences are summarized in Tables 2 and Fig. 5. The phase angle of the baseline jumps as expected as $\Delta m_{\text {cell }}$ goes through zero. The phase shift can thus be used to establish the point of asymmetry and the sign of the asymmetry. For a more accurate calculations of the phase shift, a least squares method was applied to analyze the data. Both, the instantaneously observed modulated temperature, $T$, and heat flow, $H F$, were fitted to ideal sinusoidal curves.

In conclusion, this analysis has shown that there are three methods to handle cell asymmetry in TMDSC: 1) By evaluation of the phase difference between sample and baseline run as described in Figs. 2-5. 2) By measurement of the actual cell asymmetry as a function of 
temperature using standard DSC (or from the total heat flow). 3) by using the imbalance recipe that guaranties a positive asymmetry as given in [1].

$$
\text { * } \quad * \quad *
$$

This work was supported by the Division of Materials Research, National Science Foundation, Polymers Program, Grant \# DMR 90-00520 and the Division of Materials Sciences, Office of Basic Energy Sciences, U.S. Department of Energy at Oak Ridge National Laboratory, managed by Lockheed Martin Energy Research Corp. for the U.S. Department of Energy, under contract number DE-AC05-96OR22464.

\section{REFERENCES}

1 A. Boller, I. Okazaki, K. Ishikiriyama, G. Zhang and B. Wunderlich, ICTAC 1996, Proceedings, submitted for publication in J. Thermal Analysis.

$2 \quad$ B.Wunderlich, "Thermal Analysis," Academic Press, Boston, 1990.

3 A. Boller, Y. Jin and B. Wunderlich, J. Thermal Analysis, 42, (1994) 307-330.

$4 \quad$ B. Wunderlich, "Modulated Differential Thermal Analysis." A computer generated course of 99 screens, published on the World Wide Web. For downloading look for the URL: http://funnelweb.utcc.utk.edur athas) 1995.

5 D. A. Ditmars, S. Ishihara, S. S. Chang and G. Bernstein, Journal of Research of the National Bureau of Standards, 87 (1982) 159.

6 B. Wunderlich, Y. Jin, and A. Boller, Thermochim. Acta, 238 (1994) 277.

$7 \quad$ Y. Takahashi, Thermochim. Acta, 139 (1989) 133. 


\section{Legends to the Figures:}

Fig. 1. The heat capacity for the sapphire sample and the corresponding baseline runs as a function of difference in cell imbalance expressed as difference of pan masses.

Fig. 2. The effect of positive and negative cell asymmetry for standard and modulated DSC.

Fig. 3. The relationship between modulated temperature and heat flow for sapphire and baseline runs in the case of $\Delta m=3.1 \mathrm{mg}$.

Fig. 4. The relationship between modulated temperature and heat flow for sapphire and baseline runs in the case of $\Delta m=-3.2 \mathrm{mg}$.

Fig. 5. Phase-shift difference between sapphire and empty runs as a function of $\Delta m$. The DSC cell has a cell imbalance that corresponds to $-0.6 \mathrm{mg}$ in terms of aluminum weight [1]. 


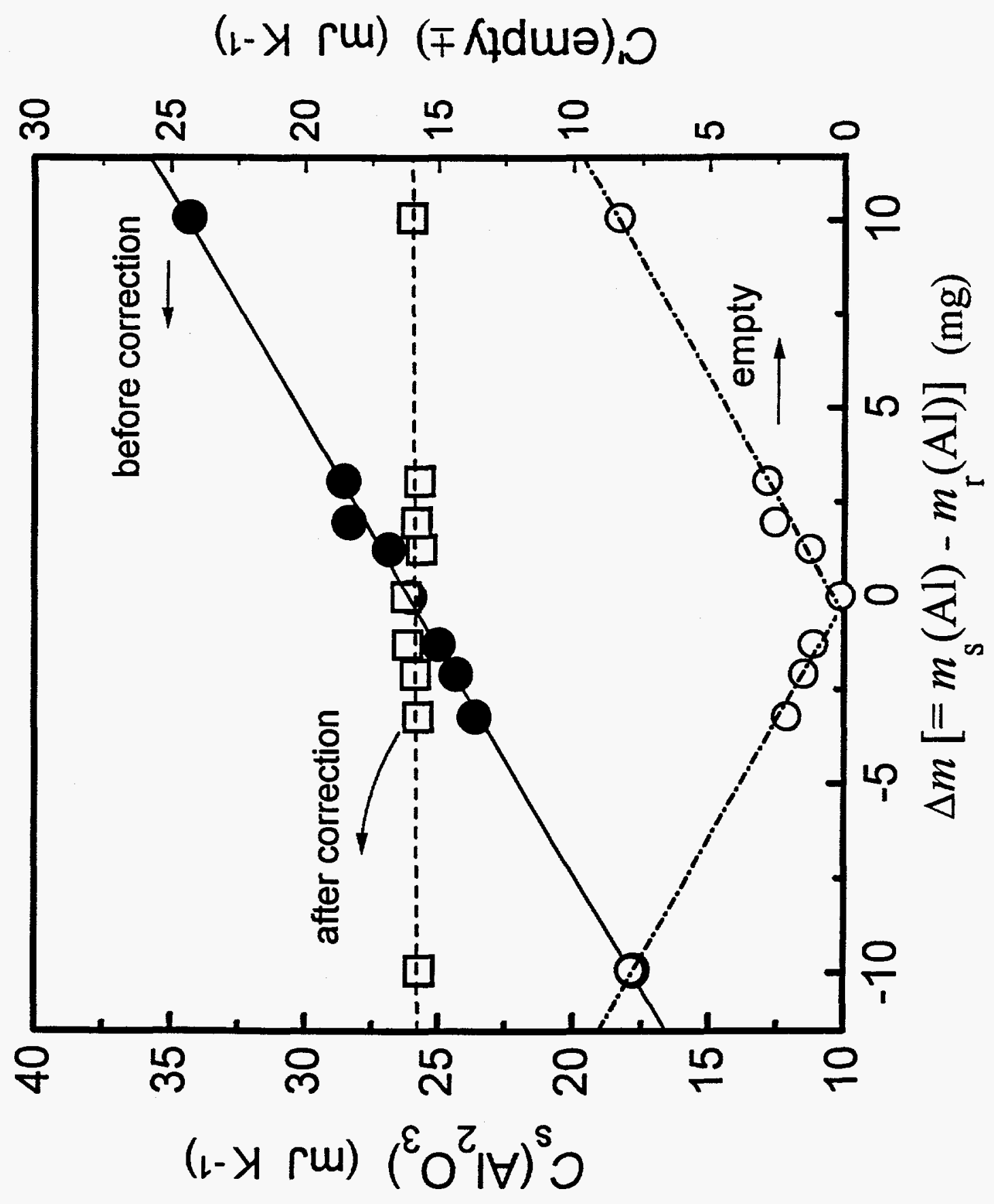

늘 


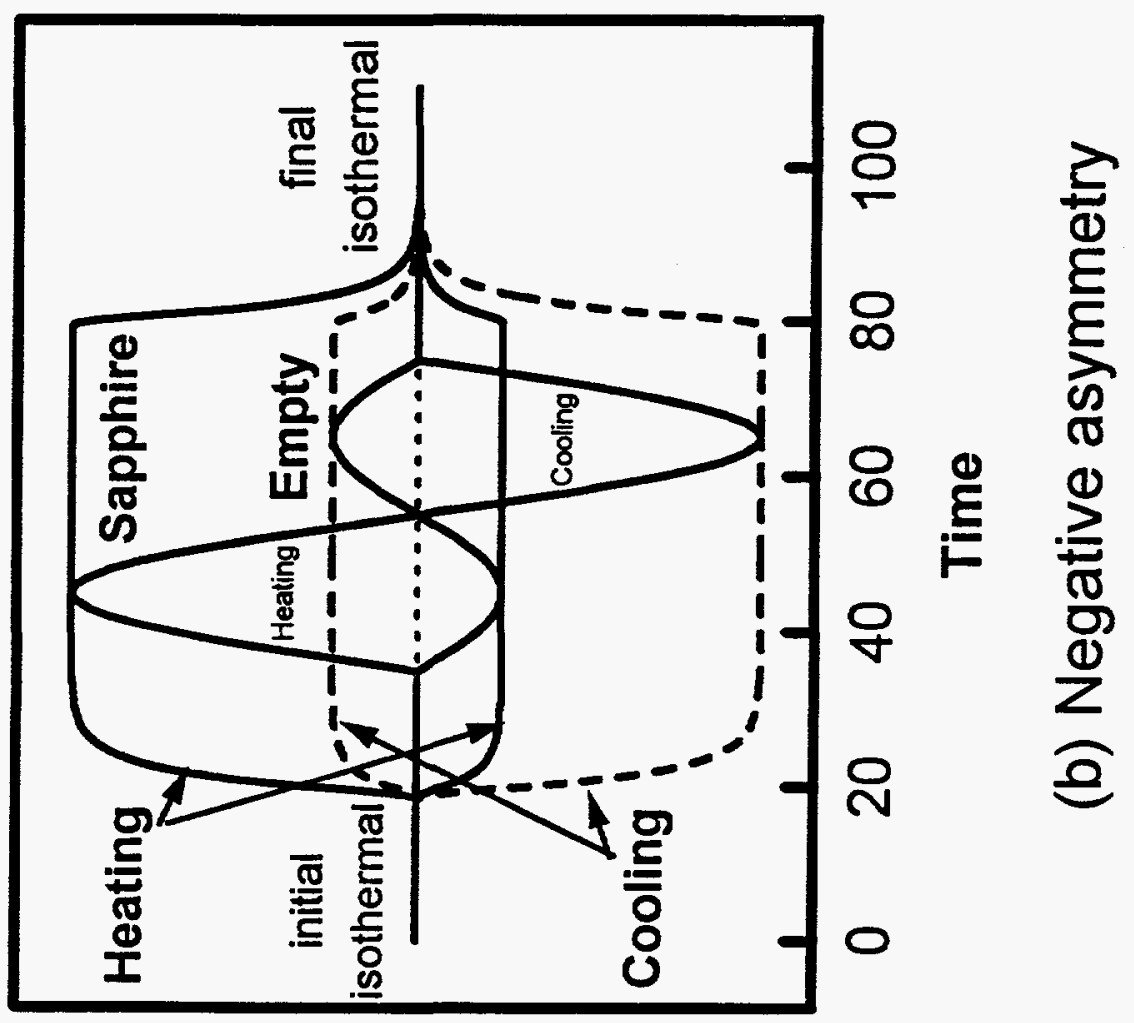

N

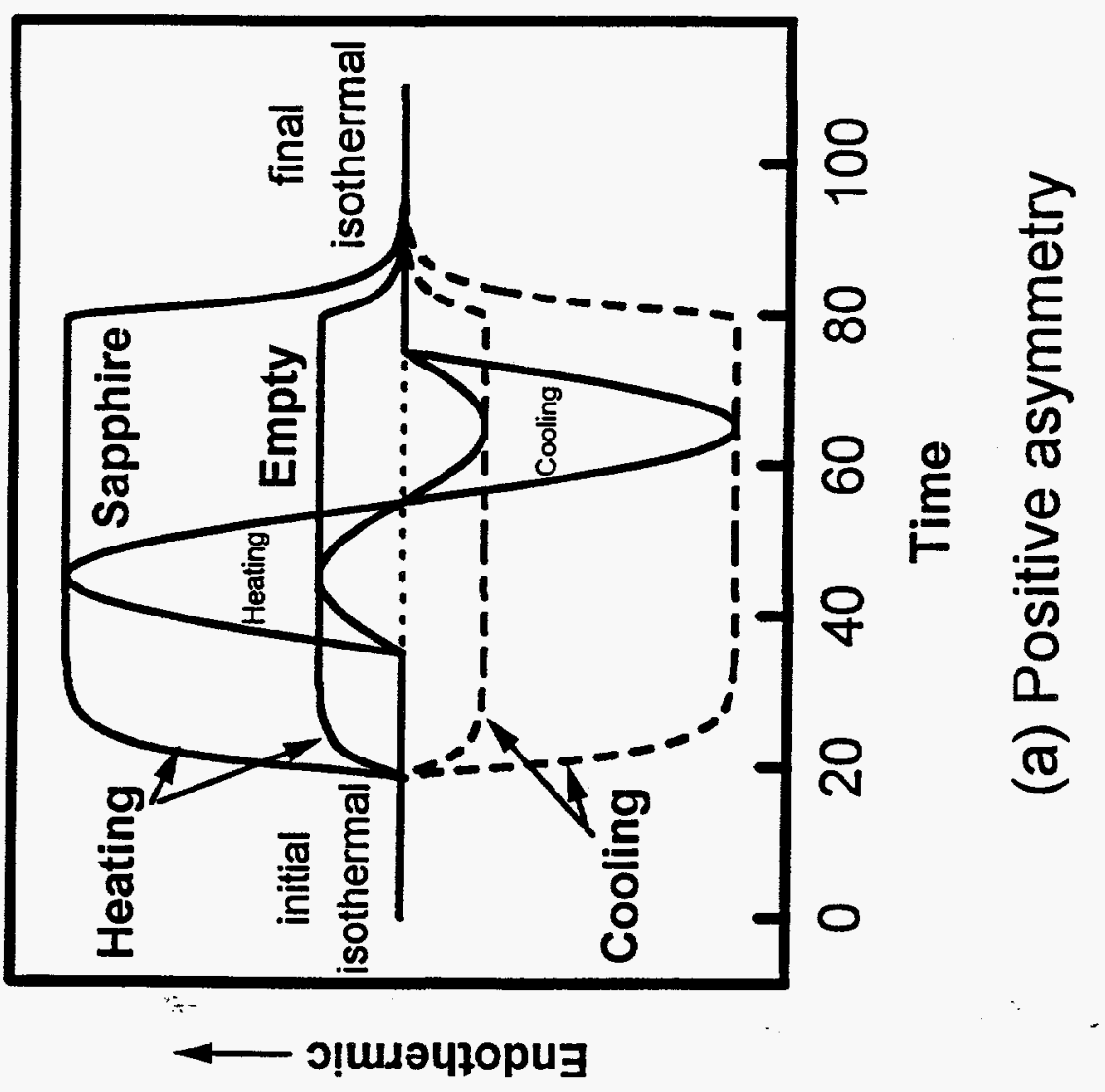




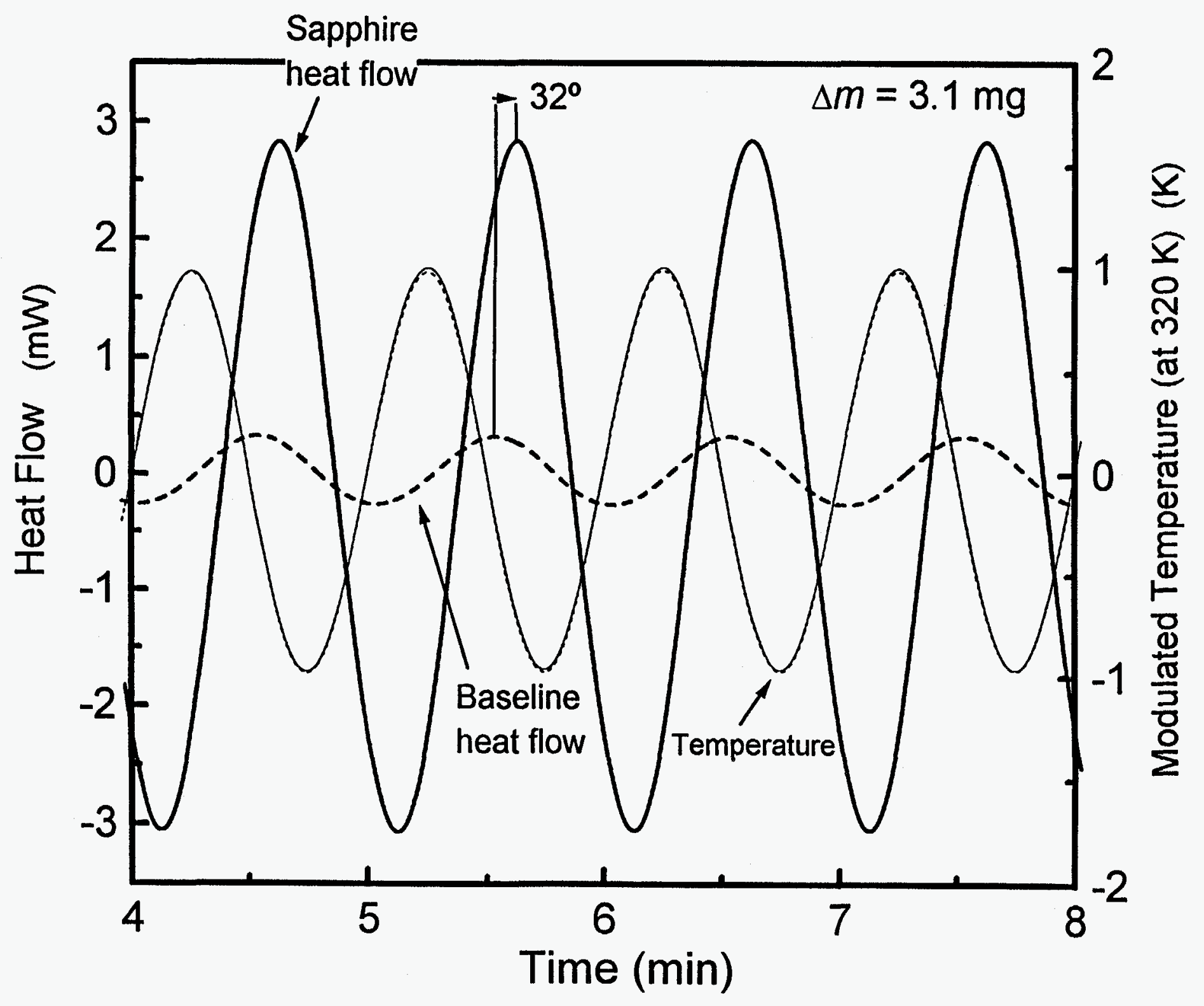

Fig. 3 
Heat Flow (mW)

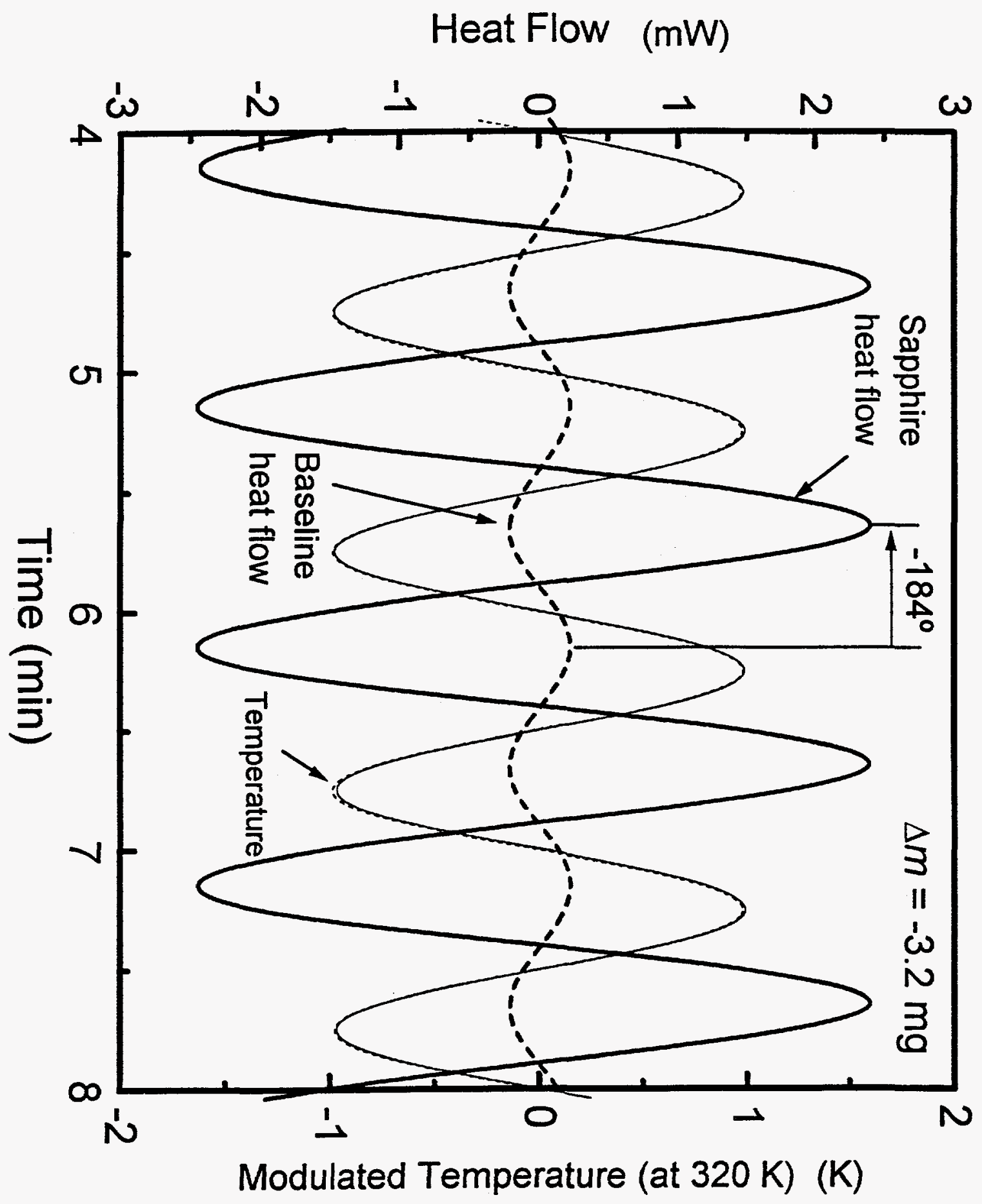

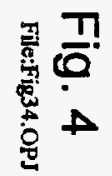




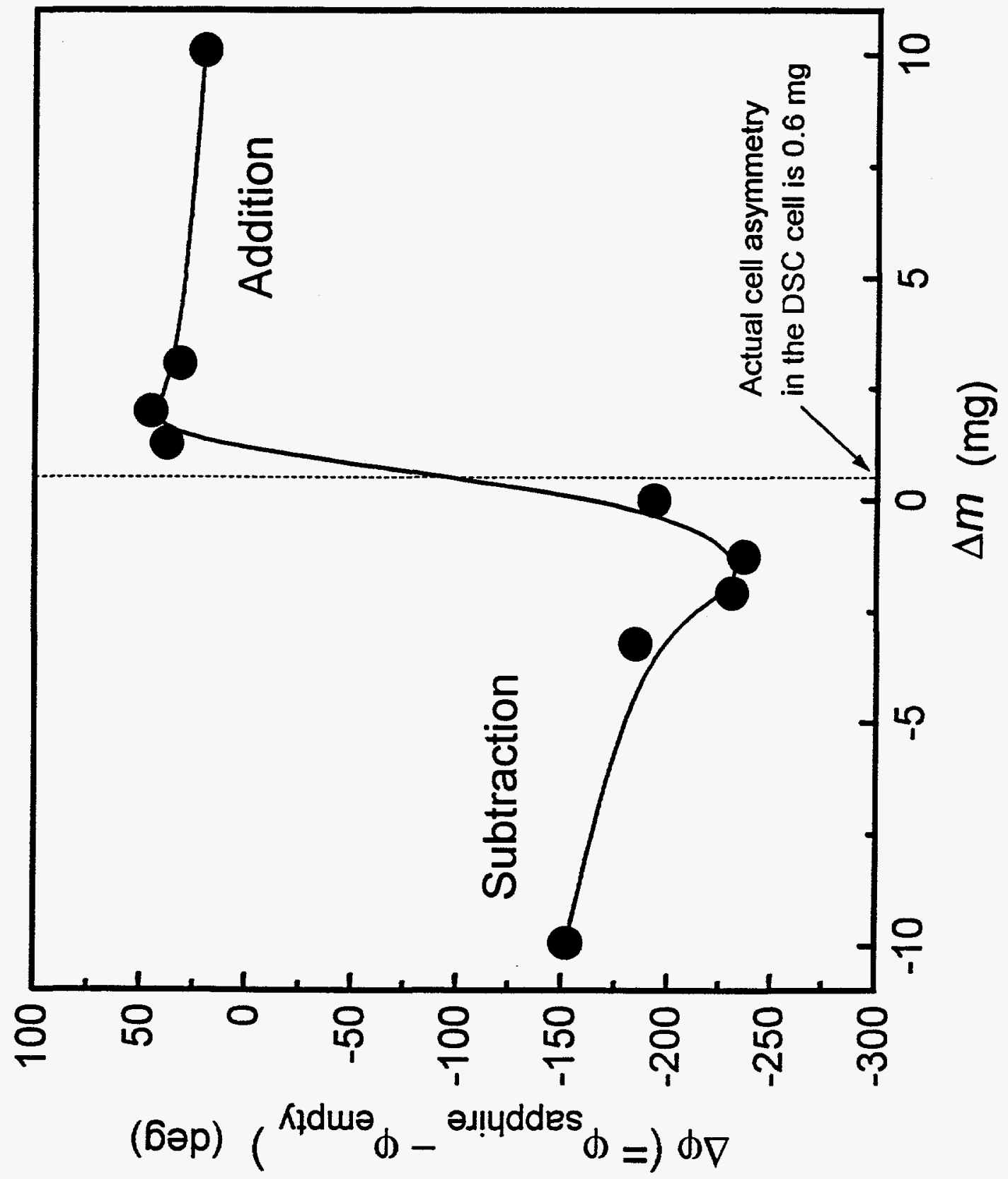


Table 1 Heat capacities of sapphire and empty pans as function of reference pan sizes at $322 \mathrm{~K}$

\begin{tabular}{|c|c|c|c|c|c|c|c|c|c|c|}
\hline run No. & $m_{\mathrm{r}}(\mathrm{Al})$ & $m_{\mathrm{s}}(\mathrm{Al})$ & $\Delta m^{\text {a) }}$ & $\left.\mathrm{C}^{\prime}(\mathrm{empty} \pm) / K_{\mathrm{c}}^{\mathrm{g}}\right)$ & $\left.C_{\mathrm{s}}\left(\mathrm{Al}_{2} \mathrm{O}_{3}\right) / K_{\mathrm{c}}^{\mathrm{g}}\right)$ & $C_{\mathrm{p}}^{\mathrm{sb})}$ & $\chi^{\mathrm{m} \mathrm{c})}$ & $C_{\mathrm{s}}\left(\mathrm{Al}_{2} \mathrm{O}_{3}\right)$ & $\left.C_{\mathrm{ps}}^{\mathrm{c}} \mathrm{d}\right)$ & $\chi^{\text {c c) }}$ \\
\hline 4 & $\mathrm{mg}$ & $\mathrm{mg}$ & $\mathrm{mg}$ & $\mathrm{mJ} \mathrm{K}^{-1}$ & $\mathrm{~mJ} \mathrm{~K}^{-1}$ & $\mathrm{~J} \mathrm{~mol}^{-1} \mathrm{~K}^{-1}$ & $\%$ & $\mathrm{~mJ} \mathrm{~K}^{-1}$ & J mol-1 $\mathrm{K}^{-1}$ & $\%$ \\
\hline $\mathrm{R} 1$ & 33.037 & 23.103 & -9.934 & 7.87 & 17.82 & 57.65 & -31.3 & $25.71^{e)}$ & 83.11 & -0.9 \\
\hline $\mathrm{R} 2$ & 26.326 & 23.103 & -3.223 & 2.13 & 23.63 & 76.45 & -8.9 & $25.81^{e)}$ & 83.34 & -0.6 \\
\hline R3 & 25.177 & 23.103 & -2.074 & 1.51 & 24.33 & 78.72 & -6.1 & $25.81^{\mathrm{e})}$ & 83.62 & -0.3 \\
\hline R4 & 24.375 & 23.103 & -1.272 & 1.17 & 24.99 & 80.84 & -3.6 & $26.21^{\mathrm{e})}$ & 84.63 & 0.9 \\
\hline R5 & 23.102 & 23.103 & 0.001 & 0.16 & 26.06 & 84.31 & 0.5 & $26.21^{\mathrm{e})}$ & 84.82 & 1.1 \\
\hline R6 & 21.835 & 23.103 & 1.268 & 1.26 & 26.88 & 86.95 & 3.7 & $25.61^{f)}$ & 82.87 & -1.2 \\
\hline R7 & 21.125 & 23.103 & 1.978 & 2.57 & 28.38 & 91.81 & 9.5 & $25.81^{f)}$ & 83.49 & -0.5 \\
\hline $\mathrm{R} 8$ & 20.045 & 23.103 & 3.058 & 2.88 & 28.60 & 92.51 & 10.3 & $25.71^{t)}$ & 83.20 & -0.8 \\
\hline R9 & 13.020 & 23.103 & 10.083 & 8.34 & 34.34 & 111.09 & 32.4 & $26.01^{f)}$ & 84.12 & 0.3 \\
\hline
\end{tabular}

a) $\Delta m=m_{\mathrm{s}}(\mathrm{Al})-m_{\mathrm{r}}(\mathrm{Al})$ difference of the aluminum mass between sample and reference pans.

b) Molar heat capacities calculated from $C_{\mathrm{s}}\left(\mathrm{Al}_{2} \mathrm{O}_{3}\right), 41.535 \mathrm{mg} \mathrm{Al}_{2} \mathrm{O}_{3}$, molar mass $101.96 \mathrm{Da}$, using $K_{\mathrm{c}}=1.318$.

c) Percentage deviation of the difference between the observed heat capacity and the literature value $\left(83.88 \mathrm{~J} \mathrm{~mol}^{-1} \mathrm{~K}^{-1}\right.$ at $322 \mathrm{~K}_{\text {[5]) }}$

d) These were calculated with Eqs. (13) and (14) using $K_{\mathrm{c}}=1.318$.

e) This value was obtained by addition of the measured heat capacities of the sapphire and empty run [Eq.(13)].

f) This value was obtained by subtraction of the measured heat capacities of the sapphire and empty run [Eq.(14)].

g) Original output signal obtained with the MDSC. 
Table 2 Phase angles

\begin{tabular}{ccccc}
\hline run No. & $\begin{array}{l}\Delta m \\
\mathrm{mg}\end{array}$ & $\begin{array}{l}\varphi_{\text {empty }}{ }^{\text {a) }} \\
\text { deg }\end{array}$ & $\begin{array}{l}\varphi_{\text {sapphire }} \text { a) } \\
\text { Reg }\end{array}$ & $\begin{array}{l}\Delta \varphi \text { b) } \\
\operatorname{deg}\end{array}$ \\
\hline R2 & -9.93 & 304.3 & 152.2 & -152.1 \\
R3 & -3.22 & 326.2 & 142.0 & -184.1 \\
R4 & -1.27 & 375.4 & 139.4 & -236.1 \\
R5 & 0.00 & 336.2 & 143.3 & -192.8 \\
R6 & 1.27 & 102.4 & 140.7 & 38.3 \\
R7 & 1.98 & 95.0 & 140.8 & 45.9 \\
R8 & 3.06 & 103.7 & 136.0 & 32.3 \\
R9 & 10.08 & 112.7 & 133.1 & 20.3 \\
\hline
\end{tabular}

a) The phase angle $\varphi$ is defined as the phase difference between the modulated heat flow and temperature, which is equal to $\delta-\varepsilon+90$. In the table, $360^{\circ}$ is appropriately added or subtracted.

b) $\Delta \varphi=\varphi_{\text {sapphire }}-\varphi_{\text {empty }}(-360)$. 